\title{
PRESERVICE TEACHERS' EXPECTATIONS OF PROFESSIONAL CONVERSATIONS ON PROFESSIONAL EXPERIENCE IN SCHOOLS
}

\author{
Denise Beutel, Donna Tangen, \& Rebecca Spooner-Lane \\ Faculty of Education, Queensland University of Technology, Queensland (Australia)
}

\begin{abstract}
Professional experience is one of the most significant learning events in preservice teacher education. The professional conversations that preservice teachers engage in with their supervising teachers while on professional experience have the potential to contribute significantly to preservice teacher learning. This qualitative research explored preservice teachers' expectations of their supervising teachers and of the professional conversations they expected to engage in while on professional experience. The participants in this research were 31 preservice teachers (17 females, 14 males) who were completing their professional experience placement in a large, urban Australian secondary school that has a highly diverse student population. The findings indicated that there was little shared understanding of the purpose and aims of professional experience by the preservice teachers and their supervising teachers. When professional conversations occurred, they focused specifically on the immediate teaching practices of the preservice teacher rather than developing a greater understanding of the broader goals of education. Further, findings revealed that while the preservice teachers were located in a highly diverse learning environment, few professional conversations focused on the diversity and uniqueness of the school context. We suggest greater shared responsibility between supervising teachers and preservice teachers and further training of supervising teachers and preservice teachers in professional dialogues as ways forward.
\end{abstract}

Keywords: Professional conversations, preservice teachers, professional experience.

\section{Introduction}

For preservice teachers, going out to schools for professional experience is one of the most significant learning events in their teacher training. There has been much written about how professional experience shapes preservice teachers' thinking and beliefs about teaching and their professional identities as teachers (Harlow \& Cobb, 2014; Timostsuk \& Ugaste, 2010). Professional experience affords preservice teachers opportunities to apply the theoretical components of teaching to real world classroom contexts (Buckworth, 2017) under the direct supervision of experienced teachers who provide guidance, feedback and support (Mena, Hennissen \& Loughran, 2017). The quality of the professional experience is recognised as the most influential aspect of teacher education programs for preservice teachers (Nielsen et al., 2017). Preservice teacher learning is contingent upon the quality of their interactions and conversations with their supervising teachers during professional experience (Helman, 2006). Professional conversations generally occur as a dyad between the preservice teacher and the supervising teacher who has been assigned to the preservice teacher at the school. These conversations allow preservice teachers opportunities to discuss in situ how teaching works. That is, preservice teachers can observe how their supervising teacher practices teaching and then engage in reflective conversations about what they observed (or understood they observed). It is through professional conversations also that preservice teachers can connect theory learnt in their coursework to actual practice in the classroom.

The role of professional conversations has gained interest in teacher education because of the potential positive impact they can have in strengthening the preservice-supervising teacher relationship. Timperley (2011) defines professional conversations as "the formal and informal dialogue that occurs between education professionals including teachers, mentors, coaches, and school leaders and is focused on educational matters" (p. 6). We extend this concept to include preservice teachers. There are many different kinds of professional conversations between preservice teachers and their supervising teachers. Feedback from supervising teachers offers one form of professional conversation. This type of conversation encourages preservice teachers to reflect on their classroom practices to consider which ones 
are working well and which aspects of practice need improvement. Establishing appropriate protocols for this type of dialogue provides a safe space for preservice teachers to engage in professional conversations (Segal, Lefstein, \& Vedder-Weiss, 2018). However, not all professional conversations are effective. According to Martinez Agudo (2016) supervising teachers generally lack training about how to provide effective feedback through engagement in professional conversations. While the ideal of professional conversations holds much promise, there is evidence that the majority of professional experiences are completed without preservice teachers engaging in any significant forms of professional conversations with their supervising teachers. The research reported on in this paper used a qualitative approach to explore preservice teachers' expectations of their supervising teachers and of the professional conversations they expected to engage in while on professional experience.

\section{The role of supervising teachers and their responsibilities}

Differing terms have been used to describe teachers who supervise preservice teachers on professional experience. Similarly, multiple terms such as field experience, practicum and clinical placements have been used to describe professional experience that is classroom-based practice in schools under the supervision of an experienced teacher. Alternate terms for the supervising teacher are cooperating teacher, school associate, sponsor teacher and mentor teacher. Supervising teacher is the term commonly used in Australia for teachers that oversee and support a preservice teacher during placement (Martinez Agudo, 2016; Nielsen et al, 2017). Nielsen et al., (2017) argue that, while "supervising" is an official term that is used widely, it connotes a task orientation whereas "mentoring" indicates a wider scope of activities used to facilitate preservice teacher learning. Further, Le Cornu and Ewing (2008) suggest that the term mentor emphasises more of a two-way collegial relationship which is mutually beneficial for the mentor and the preservice teacher rather than a hierarchical expert-novice one-way view. While we acknowledge the broad range of ways in which experienced teachers work with and support preservice teachers, we use "supervising teacher" in this paper as it is the term used in the context in which this study is situated.

Supervising teachers can instil in preservice teachers a sense of confidence, power and agency (Izadinia, 2015) or conversely, can inhibit the development of teacher identity and voice (Nielsen et al., 2017). One reason for this variance in experience may be due to supervising teachers being underprepared for the role (Nielsen et al., 2017) with few opportunities to engage in professional learning to develop skills and competencies for supervising preservice teachers. A number of authors (such as Hobson et al., 2009) report that teachers tend to model their supervision of preservice teachers on their own past experiences as preservice teachers. Burns, Jacobs and Yendol-Hoppey (2016) suggest that the protocols around supervision of preservice teachers are vaguely defined in manuals or information sheets provided to them by teacher education institutions. Supervising teachers must then make some assumptions about how to work with preservice teachers so that there is a common understanding between them and the preservice teacher as to why the preservice teacher is in the class and what they will do while there. Without clearly defined roles, supervising teachers may rely on their prior knowledge of how to supervise preservice teachers and so, in effect, are developing their own unwritten expectations which preservice teachers must then decipher in order to successfully complete their placement (Buckworth, 2017; Lafferty, 2018). Not surprisingly, if these expectations are not clearly conveyed to the preservice teacher problems may result.

Supervising teachers are expected to establish supportive relationships with the preservice teachers under their care and supervision. However, when supportive preservice teacher-supervising teacher relationships do not emerge, preservice teachers experience reduce opportunities for professional growth. One of the tensions that may arise in these relationships is when there is a mismatch between the beliefs and practices of the preservice teacher and the supervising teacher. While this difference in perspectives may offer up opportunities for rich discussions about teaching practice, some preservice teachers feel it is more judicious to 'bite one's lip and stay quiet rather than voicing their ideas. Taking on this compliant stance tends to encourage preservice teachers to simply replicate existing practices in order to fit into the school and pass their evaluations rather than engaging in critical discussions of professional practices. Rajuan, Beijaard and Verloop (2010) described this process of conforming to the expectations of the supervising teacher rather than exploring new possibilities as a 'passive socialisation into teaching' (p. 217) which allowed for little growth for the preservice teacher. 


\section{Research methods}

The qualitative research reported on in this paper is part of a wider study that was conducted in a large, urban secondary school in eastern Australia. The school has the capacity for a population of 2300 students in Grades 7 to 12 . The school has high student diversity with approximately $33 \%$ of the students speaking English as an additional language or dialect (EALD). The school commits to hosting several preservice teachers, sometimes as many as 60 at a time, drawing from four different teacher education institutions in the state. Participants in the study were 31 preservice teachers who were undertaking professional experience in the school. Data were collected through focus groups with 5-6 preservice teachers at a time. The data were analysed using content analysis (Mayring 2004) with the researchers initially analyzing their own set of data looking for emerging themes. Following this process, the researcher discussed the emergent themes and then analysed the other researcher's focus group data independently. The researchers then discussed the themes collaboratively referring back to the original data and using quotes from the transcripts to support the themes. These themes were reviewed and refined throughout the process (Schreier, 2014) until agreement was reached on a stable set of categories.

\section{Results and discussion}

In response to our first research question, what are preservice teachers' expectations of supervising teachers, two themes emerged. First, there was a wide variability in expectations and experience of the preservice teachers. The variation is exemplified in the responses of two preservice teachers. One preservice teacher participant noted that they expected that the supervising teacher would "email me what I'd be teaching and the content and any resources or anything so that I could start planning even before I came. Yeah, that didn't happen" and another noted a similar experience also in that "she [the supervising teacher] didn't know what I was going to be doing or that sort of stuff". However, at the other end of the continuum was the comment that their supervising teacher "was in contact with me really early, before I even came for an induction day" and from another "from the very first week she already told me her expectation with everything laid out". A lack of shared understandings around expectations is of concern as it may result in negative emotional experiences for preservice teachers which, in turn, may lead to negative outcomes (Buckworth, 2017). Our second theme that emerged in response to the first research question was that preservice teachers' expectations of their supervising teachers and professional experience schools may be very different from their lived experiences. For example, one preservice teacher noted that "we were given so many warnings (from uni) ... about prac ... then I came here and I was like, I can't even think of a scenario where anything would go wrong because my teachers are great, and the school support network is fantastic." Other preservice teachers noted also that professional experience "completely exceeded" their expectations.

Our second research question was what are preservice teachers' expectations of professional conversations with supervising teachers. The key theme to emerge from this research question was that the main focus of professional conversations between the preservice teachers and their supervising teachers was on quick fixes to resolve immediate classroom issues rather than on deeper discussions around broader views or perspectives of education. One preservice teacher acknowledged that the most powerful conversations they had with their supervising teacher were "a lot of feedback conversations" as it "means I can identify what's going wrong with what I can change", the focus remained on more technical aspects of classroom practice based around behavioral skills and a competency-based approach rather than a critical inquiry approach that helps teachers to become critical, reflective agents of change (Calderhead \& Shorrock, 2003). While it appeared that the preservice teachers received large volumes of feedback (such as "about 800 words of feedback each on our first lesson") the focus of the feedback was "a lot of technical talk". This finding aligns with that of Hennissen, Crasborn, Brouwer, Korthagen \& Bergen, (2008) who found that mentoring conversations with preservice teachers were mainly around instructional matters and organisation, learners and the class and subject matter. Interestingly, while the context for our study was a secondary school with the preservice teachers seen as subject experts in their fields, it appeared that few, if any, professional conversations of subject matter occurred between the preservice teachers and their supervising teachers.

Other professional conversations such as "just general checkins" were appreciated by preservice teachers. While it is important for preservice teachers to feel supported, it appeared that many of the professional conversations did not reach beyond support to more critical discussion of practice. One interesting finding to emerge from the study also was related to the pairing of the preservice teacher with the supervising teacher. While the university attempts to ensure that preservice teachers are supervised by experienced teachers on their professional experience placements, several preservice teachers noted a preference for having supervising teachers with less experience as one noted it "was helpful to have a 
teacher who's not too far out of university because she more understands how I'm feeling." There was a perception that supervising teachers who had just a few years of teaching experience were "quite empathetic and understood where we were coming from". This sentiment was expressed also by other preservice teachers in our study. It may be that having a supervising teacher closer in experience to the preservice teacher may facilitate more two-way collegial relationships (LeCornu \& Ewing, 2008) than a hierarchical expert-novice view.

\section{Implications}

From our data, it appears that there was a high degree of variability between preservice teachers' expectations and lived experiences of their interactions with their supervising teachers. While it is acknowledged that this was a small scale study conducted at one school site, and our findings are not generalisable, our data adds to the body of research around professional conversations between preservice teachers and supervising teachers. Our findings, at least, suggest that professional conversations may be falling short in terms of engaging in critical rigorous discussions of practice. Instead, it appears that professional conversations relate more to immediate issues of practice rather to more sophisticated, critical approach focused on inquiry into practice. The findings of our study have implications for teacher education, preservice teachers and supervising teachers and professional experience contexts. We suggest that preservice teachers need to be more proactive and informed in their engagements with their supervising teachers and that preservice teachers may need to drive professional conversations towards a more critical inquiry approach. It appears also from our study that supervising teachers and preservice teachers alike need training in how to engage in richer professional conversations that view schools as sites of social reform. Certainly, this area of research requires further investigation.

\section{References}

Buckworth, J. (2017). Unstated and unjust: Juggling relational requirements of professional experience for preservice teachers. Asia-Pacific Journal of Teacher Education, 45,369-382, DOI: 10.1080/1359866X.2017.1335853

Burns, R., Jacobs, J., \& Yendol-Hoppey, D. (2016). The changing nature of the role of university supervisor and functions of preservice teacher supervision in an era of clinically-rich practice. Action in Teacher Education, 38, 410-425, DOI: 10.1080/01626620.2016.1226203

Calderhead, J., \& Shorrock, S. B. (2003). Understanding teacher education: Case studies in the professional development of beginning teachers. Routledge.

Harlow, A., \& Cobb, D. J. (2014). Planting the Seed of Teacher Identity: Nurturing Early Growth through a Collaborative Learning Community. Australian Journal of Teacher Education, 39(7), n7.

Helman, L. (2006). What's in a conversation? Mentoring stances in coaching conferences and how they matter. Mentors in the making: Developing new leaders for new teachers, 69-82.

Hennissen, P., Crasborn, F., Brouwer, N., Korthagen, F., \& Bergen, T. (2008). Mapping mentor teachers' roles in mentoring dialogues. Educational Research Review 3(2)168-186.

Hobson, A. J., Ashby, P., Malderez, A., \& Tomlinson, P. D. (2009). Mentoring beginning teachers: What we know and what we don't. Teaching and Teacher Education, 25(1), 207-216.

Izadinia, M. (2015). A closer look at the role of mentor teachers in shaping preservice teachers' professional identity. Teaching and Teacher Education, 52, 1-10.

Lafferty, K. E. (2018). The difference explicit preparation makes in cooperating teacher practice. Teacher Education Quarterly, 45(3), 73-95.

Le Cornu, R. and Ewing, R., 2008. Reconceptualising professional experiences in pre-service teacher education... reconstructing the past to embrace the future. Teaching and Teacher Education, 24(7), pp.1799-1812.

Mayring, P. (2004). Qualitative content analysis. In U. Flick, E. von Kardorff, \& I. Steinke (Eds.). A companion to qualitative research (pp. 266- 275). Thousand Oaks, CA: Sage Publications.

Martinez Agudo, J. (2016). What type of feedback do student teachers expect from their school mentors during practicum experiences? The case of Spanish EFL student teachers. Australian Journal of Teacher Education, 41, DOI: 10.14221/ajte.2016.41a5.3

Mena, J., Hennissen, P., \& Loughran, J. (2017). Developing pre-service teachers' professional knowledge of teaching: The influence of mentoring. Teaching and Teacher Education, 66, 47-59.

Merriam, S. B., \& Tisdell, E. J. (2015). Qualitative research: A guide to design and implementation. New York: John Wiley \& Sons. 
Nielsen, W., Mena, J., Clarke, A., O’Shea, S., Hoban, G., \& Collins, J. (2017). Australia's supervising teachers: motivators and challenges to inform professional learning. Asia-Pacific Journal of Teacher Education, 45(4), 346-368.

Rajuan, M., Beijaard, D., \& Verloop, N. (2010). The match and mismatch between expectations of student teachers and cooperating teachers: Exploring different opportunities for learning to teach in the mentor relationship. Research Papers in Education, 25(2), 201-223.

Schreier, M. (2014). Qualitative content analysis. The SAGE Handbook of Qualitative Data Analysis, 170-183. doi.org/10.4135/981446282243.n12

Segal, A., Lefstein, A., \& Vedder-Weiss, D. (2018). Appropriating protocols for the regulation of teacher professional conversations. Teaching and Teacher Education: An International Journal of Research and Studies, 70(1), 215-226.

Timoštšuk, I., \& Ugaste, A. (2010). Student teachers' professional identity. Teaching and Teacher Education, 26(8), 1563-1570.

Timperley, H. (2011). Mentoring conversations designed to promote student teacher learning. Asia-Pacific Journal of Teacher Education, 29, DOI: 10.1080/13598660120061309

Wang, J., \& Odell, S. J. (2002). Mentored learning to teach according to standards-based reform: A critical review. Review of educational research, 72(3), 481-546. 